Vol II. No. 1, September 2017, hlm. 15 - 21

Available online at www.jurnal.una.ac.id/indeks/jmp

\title{
IMPLEMENTASI PENDEKATAN CONTEXTUAL TEACHING AND LEARNING (CTL) TERHADAP PEMBELAJARAN MATEMATIKA
}

\author{
Hariyati Ahda Nasution', Nurdalilah ${ }^{2}$ \\ Pendidikan Matematika, Universitas Muslim Nusantara Al-Washliyah Medan \\ Email: haryatiahda@yahoo.co.id.
}

\begin{abstract}
The research purpose in quasy experiment to take a researching for the implementation of contextual teaching and learning at students. The researching took at SMP Swasta Tamora 2, and it took only 73 students. The research was an experimental stdy by pretest posttest control group design. Population in researching were all of the students at grade VII an it took two samples class (experiment class and control class) by purposive sampling. The data were analyzed by independent sample $\mathrm{T}$ test. Before using independent sample $t$ test, it took a test for homogeneity and normality in significance level at 5\%. The analyzing result for students ability in mathematic communication at experiment class was 29,94 and 22,46 at control class. Based on independent sample t test significance value was $\alpha=0,03$. Because significance value was less than $\alpha=0,05$, it means the students get a better result by contextual teaching and learning methode than conventional teaching learning.
\end{abstract}

Keyword : Pendekatan Contextual Teaching Learning (CTL), Mathematic Learning.

\begin{abstract}
Abstrak
Tujuan penelitian dalam desain Eksperimen semu ini menyelidiki implementasi pendekatan contextual teaching and learning (CTL) terhadap pembelajaran matematika pada siswa. Penelitian ini dilaksanakan di SMP Swasta Tamora 2 sebanyak 73 siswa. Penelitian ini merupakan suatu studi eksperimen dengan desain penelitian pre-test-posttest control group design., populasi dalam penelitian ini adalah seluruh siswa kelas VII dengan mengambil sampel dua kelas (kelas eksperimen dan kelas kontrol) melalui teknik purposive sampling. Data dianalisis dengan uji Independent Sample t Test. Sebelum digunakan uji Independent Sample t Test terlebih dahulu dilakukan uji homogenitas dalam penelitian dan normalitas dalam penelitian ini dengan taraf signifikan 5\%. Hasil analisis rata-rata kemampuan komunikasi matematik siswa pada kelas eksperimen sebesar 29,94dan pada kelas kontrol 22,46 dan berdasarkan hasil uji Independent Sample t Test diperoleh signifikansi $\alpha=0,03$. Karena taraf nilai signifikan hasil belajar lebih kecil dari $\alpha=0,05$, maka dapat disimpulkan bahwa hasil belajar matematik siswa yang diajarkan dengan pembelajaran contextual teaching and learning lebih tinggi dibandingkan dengan pembelajaran konvensional.
\end{abstract}

Kata kunci : Pendekatan Contextual Teaching Learning(CTL), Pembelajaran matematik 
Vol II. No. 1, September 2017, hlm. 15 - 21

Available online at www.jurnal.una.ac.id/indeks/jmp

Matematika merupakan ilmu pengetahuan yang aplikasinya sangat mempengaruhi perkembangan ilmu pengetahuan dan teknologi. Kemampuan matematika selalu dibutuhkan, tidak hanya dibidang matematika saja, tetapi juga mempengaruhi cabang ilmu lainnya.Selain itu, banyak fenomena yang selalu kita jumpai dan itu menerapkan prinsip-prinsip matematika dalam kehidupan seharihari.Cronbach dalam Riyanto, (2009 : 5) mengemukakan bahwa : "Belajar merupakan perubahan perilaku sebagai hasil dari pengalaman.”.

Matematika juga berfungsi mengembangkan kemampuan menghitung, mengukur dan menggunakan rumus matematika yang diperlukan dalam kehidupan sehari-hari melalui materi pengukuran dan geometri, serta aljabar dan trigonometri.Dalam proses pembelajaran matematika selama ini, guru menerapkan strategi klasikal dengan metode ceramah menjadi pilihan utama sebagai metode pembelajaran. Pola pembelajaran atau urutan sajian materi dalam pembelajaran matematika yang biasa dilakukan selama ini adalah (1) pembelajaran diawali penjelasan singkat materi oleh guru, siswa diajarkan teori, defenisi, teorema yang harus dihafal, (2) pemberian contoh soal dan (3) diakhiri dengan latihan soal. Dalam pembelajaran ini konsep yang diterima siswa hampir semuanya berasal dari "apa kata guru".Konsekwensinya, bila siswa diberikan soal yang berbeda dengan soal latihan, maka siswa cenderung membuat kesalahan.Pengetahuan yang dimiliki siswa hanya bersifat prosedural yaitu siswa cenderung menghafal contoh-contoh yang diberikan oleh guru tanpa terjadi pembentukan konsepsi yang benar dalam struktur kognitif siswa.. Keadaan seperti ini membuat siswa mengalami kesulitan memahami konsep matematika sehingga sangat mudah terjadi miskonsepsi yang nantinya akan

menyebabkan siswa mengalami kesulitan memahami konsep lebih lanjut.

Penerapan pembelajaran kontekstual diduga dapat memberikan sumbangan alternatif pemecahan masalah pembelajaran matematika, khususnya dalam meningkatkan hasil belajar matematika siswa.Dalam kegiatan pembelajaran dengan pendekatan kontekstual guru mengarahkan siswa untuk mengkonstruksi pengetahuannya sendiri terhadap pemahaman konsep yang diberikan.Ini dilakukan guru dengan memanfaatkan pengetahuan awal siswa tentang materi yang dijelaskan.Pengetahuan awal tersebut dapat berupa benda-benda konkrit yang ditemukannya dalam kehidupan seharihari atau dapat juga menggunakan simbol-simbol yang mudah dipahami siswa.

Pendekatan kontekstual juga dapat mengaktifkan yang dimiliki siswa, sehingga hasil belajar siswa dapat ditingkatkan.Pembelajaran kontekstual merupakan pembelajaran yang menekankan pada tingkat berpikir yang tinggi, yaitu berpikir divergen (kreatif) (Depdiknas, 2005). Sedangkan pembelajaran matematika yang menggunakan pembelajaran konvensional cenderung mengarahkan siswa untuk memberi respon yang 
Vol II. No. 1, September 2017, hlm. 15 - 21

Available online at www.jurnal.una.ac.id/indeks/jmp

tunggal terhadap permasalahan yang diberikan.

\section{METODE}

Penelitian ini terdiri dari tahap persiapan dan tahap pelaksanaan. Pada tahap persiapan penelitian ini dilakukan beberapa kegiatan, yaitu: (a) mengembangkan perangkat pembelajaran (bahan ajar dan lembar aktivitas siswa), (b) menyusun insturumen, (c) mengujicobakan soalsoal tes kemampuan komunikasi matematik siswa, (e) merevisi perangkat pembelajaran, dan (f) memilih sampel secara purposive sampling terhadap seluruh siswa kelas VII sebanyak dua kelas untuk dijadikan sebagai kelompok pembelajaran berbasis masalah dan kelompok pembelajaran langsung.

Sedangkan tahap pelaksanaan diawali dengan memberikan pretes sebelum pembelajaran terhadap materi baru diberikan kepada siswa. Tes materi prasyarat ini diberikan kepada siswa kelas VII pada kelompok pembelajaran contextual teaching learning dan pembelajaran konvensional dengan tujuan agar kedua kelompok memiliki kemampuan yang telah ditetapkan.

Populasi dalam penelitian ini adalah seluruh siswa SMP Swasta Tamora 2 Kabupaten Deli Serdang yang terdiri dari dua kelas dengan jumlah keseluruhan 82 orang. Sebagai subyek sampel dalam penelitian ini, secara acak dipilih dua kelas dari empat kelas yang ada di SMP tersebut. Dari pemilihan acak tersebut maka terpilihlah siswa kelas VII-1 dan VII-2 yang kemudian secara acak dipilih pula kelas eksperimen dan kelas kontrol. Dalam penelitian ini terpilih kelas VII-
2 sebagai kelas eksperimen dan VII-1 sebagai kelas kontrol, dengan jumlah siswa pada kelas VII-1 sebanyak 42 siswa dan kelas VII-2 sebanyak 42 siswa.

Teknik pengumpulan data dalam penelitian ini menggunakan tes. Ridwan (2006) mengatakan tes adalah serangkaian pertanyaan atau latihan yang dugunakan untuk mengukur keterampilan pengetahuan, intelegensi, kemampuan atau bakat yang dimiliki individu atau kelompok.

Untuk pengolahan data diawali dengan mendeskripsikan hasil belajar dengan menghitung rata-rata dan standar deviasi, uji normalitas dan homogenitas kemudian selanjutnya dilakukan uji dua rata-rata untuk menguji hipotesis.

\section{HASIL DAN PEMBAHASAN}

Setelah dilakukan pretest dan postest kepada siswa diperoleh nilai rata-rata (mean) masing-masing kelas untuk melihat apakah pendekatan contextual teaching and learning pada siswa memperoleh hasil pembelajaran matematika yang lebih meningkat dibandingkan pembelajaran konvensional. Rata-rata hasil belajar matematik siswa pada kelas eksperimen sebesar 27,94 dan pada kelas kontrol sebesar 22,4. Untuk mengetahui peningkatan hasil belajar melalui pembelajaran contextual teaching learning dan siswa yang diberi model pembelajaran konvensional digunakan independent sampel t test. Sebelumnya dari data diketahui bahwa data berdistribusi normal dan homogeny, terlihat pada tabel dibawah ini. 


\section{MATEMATICS PAEDAGOGIC}

Vol II. No. 1, September 2017, hlm. 15 - 21

Available online at www.jurnal.una.ac.id/indeks/jmp

Tabel 1. Uji normalitas data hasil pembelajaran matematik

One-Sample Kolmogorov-Smirnov Tes

\begin{tabular}{|ll|r|r|}
\hline & & $\begin{array}{c}\text { Contextual } \\
\text { teaching } \\
\text { learning }\end{array}$ & Konvensional \\
\hline $\mathrm{N}$ & Mean & 35 & 35 \\
Normal & 27.94 & 22.46 \\
Parameters(a,b) & Std. Deviation & 10.307 & 10.359 \\
Most Extreme & Absolute & .203 & .221 \\
Differences & Positive & .203 & .221 \\
& Negative & -.126 & -.136 \\
Kolmogorov-Smirnov Z & & 1.203 & 1.310 \\
Asymp. Sig. (2-tailed) & & .111 & .065 \\
\hline
\end{tabular}

a Test distribution is Normal.

b Calculated from data.

Berdasarkan Tabel 1 di atas diperoleh bahwa pembelajaran contextual teaching and learning kelas eksperimen dan pembelajaran konvensional kelas kontrol memiliki nilai signifikansi yang lebih besar dari
0,05 yaitu $(0,111>0,05)$ dan $(0,65>$ 0,05) maka data pembelajaran contextual teaching and learning dan pembelajaran konvensional

Tabel 2. Uji Homogenitas Data Hasil Belajar Matematik

\begin{tabular}{|c|c|c|c|}
\hline $\begin{array}{c}\text { Levene } \\
\text { Statisti } \\
\text { c }\end{array}$ & df1 & df2 & Sig. \\
\hline 1.726 & 9 & 23 & .140 \\
\hline
\end{tabular}

Tabel 3. Analisis statistik Independent Sample t Test

\begin{tabular}{|ll|c|c|c|c|c|}
\hline \multirow{2}{*}{} & & \multicolumn{2}{|c|}{$\begin{array}{c}\text { Levene's Test for } \\
\text { Equality of } \\
\text { Variances }\end{array}$} & \multicolumn{2}{|c|}{ t-test for Equality of Means } \\
\cline { 2 - 7 } & $\mathrm{F}$ & Sig. & $\mathrm{t}$ & Df & Sig. (2-tailed) \\
\cline { 2 - 7 } & & & & & \\
\hline $\begin{array}{l}\text { Pemb } \\
\text { elajar } \\
\text { an }\end{array}$ & $\begin{array}{l}\text { Equal variances } \\
\text { assumes }\end{array}$ & .532 & .468 & 2.221 & 68 & \\
& $\begin{array}{l}\text { Equal variances } \\
\text { not assumes }\end{array}$ & & & 2.221 & 67. & \\
\hline
\end{tabular}


Vol II. No. 1, September 2017, hlm. 15 - 21

Available online at www.jurnal.una.ac.id/indeks/jmp

Berdasarkan Tabel 2 memberikan nilai significance (sig.) lebih besar dari $\alpha=0,05$, maka $\mathrm{H}_{0}$ diterima. Dengan demikian kedua sampel berasal dari populasi yang memiliki varians yang homogen.

Berdasarkan hasil analisis ratarata kemampuan komunikasi matematik siswa pada kelas eksperimen sebesar 29,94dan pada kelas kontrol 22,46 dan berdasarkan hasil uji Independent Sample $\mathrm{t}$ Test diperoleh signifikansi $\alpha=0,03$. Karena taraf nilai signifikan hasil belajar lebih kecil dari $\alpha=0,05$, maka dapat disimpulkan bahwa hasil belajar matematik siswa yang diajarkan dengan pembelajaran contextual teaching and learning lebih tinggi dibandingkan dengan pembelajaran konvensional.

\section{SIMPULAN}

Berdasarkan hasil analisis dan pembahasan dalam penelitian ini, dapat disimpulkan bahwa: Hasil belajar matematik siswa yang diajarkan dengan pembelajaran contextual teaching and learning lebih tinggi dibandingkan dengan pembelajaran konvensional

\section{Saran}

Penelitian mengenai penerapan pembelajaran dengan contextual teaching learning ini, masih merupakan langkah awal dari upaya meningkatkan kompetensi dari guru, maupun kompetensi siswa. Oleh karena itu, berkaitan dengan temuan dan kesimpulan dari studi ini dipandang perlu agar rekomendasi-rekomendasi

berikutnya dilaksanakan oleh guru matematika SMP, lembaga dan peneliti lain yang berminat. 1)Kepada Guru: Pembelajaran contextual teaching dapat diterapkan pada semua kategori. Oleh karena itu hendaknya pendekatan ini terus dikembangkan di lapangan yang membuat siswa terlatih dalam memecahkan masalah. Peran guru sebagai fasilitator perlu didukung oleh sejumlah kemampuan antara lain kemampuan memandu diskusi di kelas, serta kemampuan dalam menyimpulkan. Di samping itu kemampuan menguasai bahan ajar sebagai syarat mutlak yang harus dimiliki guru. Untuk menunjang keberhasilan implementasi pembelajaran contextual teaching and learning diperlukan bahan ajar yang lebih menarik dirancang berdasarkan permasalahan kontektual yang merupakan syarat awal yang harus dipenuhi sebagai pembuka belajar mampu stimulus awal dalam proses pembelajaran yang dilaksanakan.2) Kepada peneliti yang berminat: Untuk penelitian lebih lanjut hendaknya penelitian ini dapat dilengkapi dengan meneliti aspek lain secara terperinci yang belum terjangkau saat ini.

\section{DAFTAR RUJUKAN}

Depdiknas .(2005). Kurikulum 2004 Standar Kompetensi Mata Pelajaran Matematika.Jakarta.
Nurhadi, dkk.2002. Pembelajaran Kontekstual (Contextual
Teaching and Learning/CTL)
dan Penerapannya dalam 


\section{Gurnal \\ MATEMATICS PAEDAGOGIC}

Vol II. No. 1, September 2017, hlm. 15 - 21

Available online at www.jurnal.una.ac.id/indeks/jmp

\begin{tabular}{crrr} 
KBK. Malang: Universitas & Sudjana. 2005. Metoda \\
Negeri Malang. & \multicolumn{2}{c}{ Bandung: Tarsito } \\
Ridwan. & 2004. Belajar $\quad$ Mudah \\
Penelitian untuk & Sudijono, Anas. 2007. Pengantar \\
Karyawan dan Penelitian. & Statistik Pendidikan. Jakarta : \\
Bandung. Alfabeta & Rajawali & Pers.
\end{tabular}


Vol II. No. 1, September 2017, hlm. 15 - 21

Available online at www.jurnal.una.ac.id/indeks/jmp 